\title{
Treatment of Mycobacterium marinum with lymecycline: new therapeutic alternative?
}

\author{
Maria Gertrudes Fernandes Pereira Neugebauer ${ }^{1}$ \\ Hiram Larangeira Almeida Junior ${ }^{1}$
}

\author{
Samuel Antônio Neugebauer ${ }^{1}$ \\ Laís Marques Mota ${ }^{1}$
}

\begin{abstract}
Skin infections by Mycobacterium marinum are quite rare in our environment and, therefore, little studied. The majority of the lesions appear three weeks after traumas in aquariums, beaches and fish tanks. Lymph node drainage and systematization of the disease are rare and most lesions disappear in about three years. This case aims to show the effectiveness of the treatment used (lymecycline $150 \mathrm{mg} /$ orally/day). This medication may be a new therapeutic option for the treatment of Mycobacterium marinum.
\end{abstract}

Keywords: Fish diseases; Fishes; Lymecycline; Mycobacterium marinum

\section{INTRODUCTION}

In 1926, while examining dead fish, Aronson found tuber bacilli inside them. These bacilli were different from those already described and were named Mycobacterium marinum. ${ }^{1}$

In 1954, Linell and Norden described M. marinum as a cause of human skin infection for the first time. These lesions resembled tuberculosis verrucae cutis and are characterized by papules, nodules and ulcers with or without exudation. ${ }^{2}$ The majority of the lesions appear three weeks after traumas in aquariums, beaches, fish tanks. Lymph node drainage and systemization of the disease are rare and most lesions disappear in about three years.

Histological examination reveals granulomatous inflammation with epithelial cells, giant cells, caseous necrosis and abscesses.

As to epidemiology, the largest reported epidemic occurred in Colorado, United States, with 290 cases being described by Philpott et al. ${ }^{3}$

The majority of infections occur on the back of hands, fingers and elbows. The lesions may initially be solitary or multiple nodules, progress to ulceration and, finally, become exuding wounds. Satellite lesions occur frequently and, in some cases, are raised like lymphangitic sporotrichosis.

The best way to cultivate Mycobacterium marini$u m$ is between 86 and $91,4^{\circ} \mathrm{F}$, in Lowenstein Jensen medium. ${ }^{4}$ The colonies become visible in 8-14 days. The examination of the culture of this mycobacterium has important characteristics because they are photochromic (Figure 1). In the dark they are white and when exposed to light they become yellow or orange. Positive tuberculin reaction happens in $82 \%$ of the cases.

Winter and Runyon made an important consideration on $M$. marinum since it can parasitize fish, cold-blooded and warm-blooded animals, including humans, showing a significant variation in the capacity of their habitat. ${ }^{5}$

Hyperkeratosis, parakeratosis, inflammatory granuloma, lymphocytes, histiocytes, epithelioid cells and Langerhans cells characterize the histology.

\footnotetext{
Received on 28.05.2013.

Approved by the Advisory Board and accepted for publication on 30.10.2013.

* Work performed at the Universidade Federal de Pelotas (UFPel) - Pelotas (RS), Brazil.

Financial Support: none

Conflict of Interests: none

Universidade Federal de Pelotas (UFPel) - Pelotas (RS), Brazil.

(C2015 by Anais Brasileiros de Dermatologia
} 


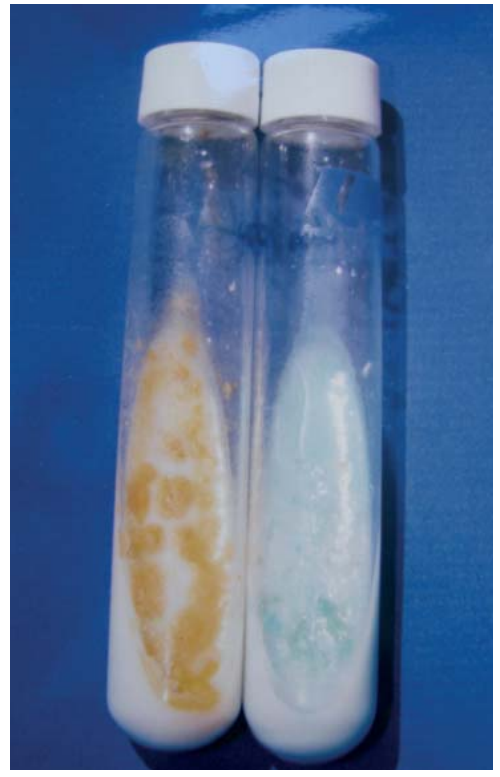

Figure 1:

Photochromic

colonies. On the

right side, a normal culture. On the left side, yellow-orange material that was exposed to light and for this reason is called photocromic

The main differential diagnoses are tuberculosis verrucosa cutis, sporotrichosis, leishamaniasis, verruca vulgaris, tularemia, nocardiosis, blastomycosis, coccidioidomycosis, tumors and others.

\section{CASE REPORT}

An 18 year-old single white female patient, born and raised in Pelotas, southern Brazil, reported having suffered slight scratches on the back of her right hand (while cleaning the glass wall of an aquarium). The fish that lived there died a week later. After three months, she noticed the lesion was difficult to heal and, after using many medications, including antibiotics, she sought medical care from a specialist. The dermatological examination revealed two ulcerated nodular lesions with abundant exudate located on the middle finger and on the back of the right hand, with the presence of nodular type satellite on the wrist of the same hand, resembling a sporotrichoid infection (Figure 2). Physical examination found no other changes.

In the laboratory investigation, material was collected for skin testing for fungus and bacteria, as well as skin fragment for a biopsy. Mycological examination was negative. On the other hand, bacteriologic test was positive after 10 days, with growth of mycobacterium that, according to photochromic characteristics, was identified as Mycobacterium marinum. The histological report was descriptive, showing granulomatous inflammatory infiltrate with giant cells, mixed inflammatory cells and the presence of necrosis, suggestive of granulomatous disease. It is known that tetracyclines are an alternative therapy for mycobacteriosis. We chose to start treatment with one drug of this class, lymecycline $150 \mathrm{mg} /$ orally/day, due to history of gastritis triggered by previous antibiotic treatments, since this drug is better tolerated. After 10 days of treatment, she had clear signs of lesion improvement and we chose to keep the treatment and reevaluate after 45 days (Figure 3). After this period, the patient returned to the clinic with total remission of lesions; we decided then to suspend all medication and discharged the patient, in view of the good development, thereby obtaining a clinical cure.
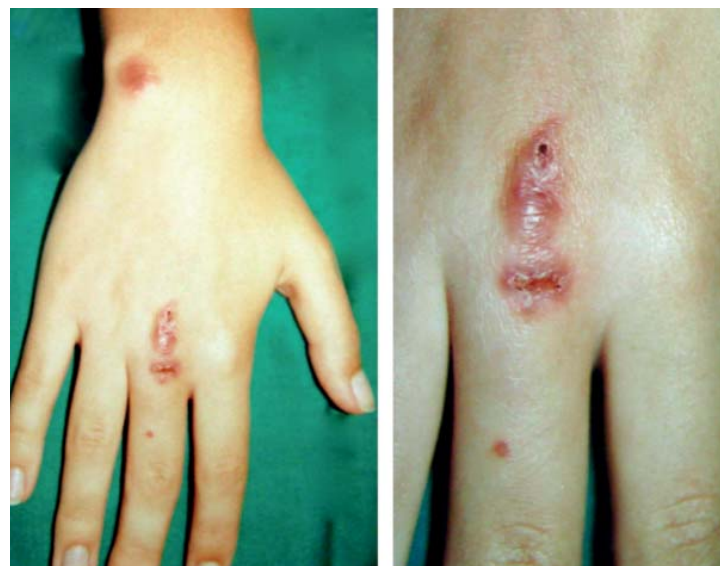

FIGURE 2: Ulcerated nodular lesions. Lesions at first dermatological appointment

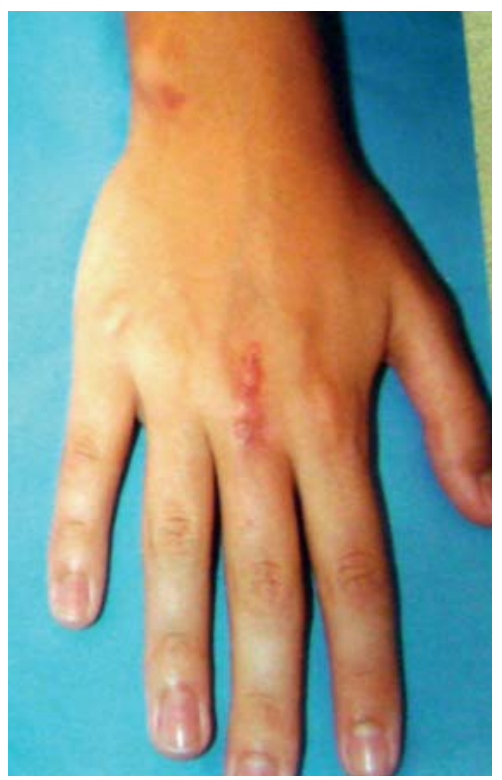

Figure 3: Lesion showing evident clinical improvement. After 10 days of treatment with lymecycline $150 \mathrm{mg}$ $\mathrm{VO} /$ day, important clinical improvement could already be observed 


\section{DISCUSSION}

Infection caused by Mycobacterium marinum is quite rare in our country, therefore it has been little studied. In the case discussed, the contagion was in a domestic aquarium, and it is a warning for special care when handling this type of container, in view of the Brazilian habit of manipulating fish in aquariums. We stress the importance of this case because it had a great therapeutic response to low doses of lymecycline (150mg/orally/day), since the usual dose for adults with other conditions is $300 \mathrm{mg}$ daily. Resistance to antibiotics and chemotherapy characterizes mycobac- terial infections. Several studies have reported long treatment periods ranging from several months to years using the traditional medications. ${ }^{2}$ There are also reports of increased resistance to therapy when there is sporotrichoid lymphangitic dissemination, when usually are used antitubercular multiple drug treatments, as rifampicin and ethambutol. ${ }^{4}$ We suggest further studies for possible inclusion of lymecycline in the therapeutic arsenal for treating these mycobacteria, since the dosage is simple, there is low rate of adverse reactions and excellent digestive tolerance.

\title{
REFERENCES
}

1. Aronson JD. Spontaneous tuberculosis in salt water fish. $J$ Infect Dis. 1926;39:315-20.

2. Linell F, Nordén A. Mycobacterium balnei: a new acid-fast bacillus occurring in swimming pools and capable of producing skin lesions in humans. Acta Tuberc Scand Suppl. 1954:33:1-84.

3. Philpott JA Jr, Woodburne AR, Philpott OS, Schaefer WB, Mollohan CS. Swimming pool granuloma: a study of 290 cases. Arch Dermatol. 1963;88:158-62.

4. Ishikawa CM, Matushima ER, Souza CW, Timenetsky J, Paiva MJ. Micobacteriose em peixes. Boletim do Instituto de Pesca, São Paulo. 2001;27;231-42.

5. Winter FE, Runyon EH. Prepetellar bursitis caused by Mycobactrium marinum (balnei); case report, classification, and review of the literature. J Bone Joint Surg Am. 1965;47:375-9.

\author{
MAILING ADDRESS: \\ Maria Gertrudes Fernandes Pereira Neugebauer \\ Rua General Osório, 956 \\ Centro \\ 96020-000 Pelotas - RS. \\ E-mail: gertrudes.atos@terra.com.br
}

How to cite this article: Neugebauer MGFP, Neugebauer AS, Almeida Jr HL, Mota LM. Treatment of Mycobacterium marinum with lymecycline: new therapeutic alternative? An Bras Dermatol. 2015;90(1):117-9. 